\title{
Earthquake fault framework and seismotectonics of the Songpan-Garze region since 1900*
}

\author{
Jiasheng Zhang, ${ }^{1, *}$ Weijun Gan ${ }^{1}$ Minghua Zhang ${ }^{2}$ \\ Xiongnan Huang ${ }^{1}$ and Feng Liu ${ }^{1}$ \\ ${ }^{1}$ Institute of Geology, China Earthquake Administration, Beijing 100029, China \\ ${ }^{2}$ Development Research Center of China Geological Survey, Beijing 100037, China
}

\begin{abstract}
Based on 4781 observed faults (>2 km length) from a 1:200 000 scale digital geologic map and 5220 recorded seismic events since the year 1900, 993 earthquake faults are identified within the triangular Songpan-Garze study region. The study area is delineated by the nearly EW-trending East Kunlun fault zone to the north, the NW-trending Xianshuihe fault to the south and the NE-trending Longmenshan thrust belt to the east. Seismicity changes along these earthquake faults, spanning four 10-year intervals since 1970, show that following a strong earthquake swarm, which occurred in the Huya area in the mid-1970s, seismic activity increased from north to south, and migrated eastward along each major strike-slip fault zone. GPS observation data before 2008 indicate a displacement rate across the Xianshuihe fault zone to the south of $\sim 6.5-8.6 \mathrm{~mm} / \mathrm{a}$, whereas across the East Kunlun fault zone to the north it was $\sim 1.8-2.2 \mathrm{~mm} / \mathrm{a}$. The May 12, $2008 M_{\mathrm{S}} 8.0$ Wenchuan earthquake, which occurred in the southeast corner of the study region, was the result of stable, high-speed left-lateral displacement along the Xianshuihe fault zone, and a sharp eastward bend of the fault trend in response to the presence of crystalline rocks in the Kangding area. Therefore, the 110-year established seismotectonic framework of the Songpan-Garze region can be defined by a network of various earthquake faults and the structural relations of the local earthquake activities.
\end{abstract}

Key words: Songpan-Garze region; earthquake fault; GPS; Wenchuan earthquake CLC number: P315.2 Document code: A

\section{Introduction}

Although the preparation processes and the ultimate triggering mechanisms of an earthquake are a long-standing controversy (Denham, 1988; Stein and Yeats, 1989; Cyranoski, 2004) that have complicated earthquake prediction (Chui, 2009), the correlation between seismicity and fault location is generally accepted. Intensive fracturing and fine-grained sheared material along fault planes in broad deformation zones results in weakness areas in the crust where displacement accumulation can become localized, and therefore being the primary location for earthquake nucleation.

\footnotetext{
* Received 15 May 2012; accepted in revised form 5 August 2012; published 10 December 2012.

^ Corresponding author. e-mail: jszhang@public3.bta.net.cn

(C) The Seismological Society of China, Institute of Geophysics, China Earthquake Administration, and Springer-Verlag Berlin Heidelberg 2012
}

Fault growth and earthquake activity are inseparable. All faults, whether active or inactive, are potential sites of earthquake nucleation when their orientation is optimum for the existing state of stress. Therefore, quantitatively assessing the seismic history of a fault is of great significance for understanding the future seismic behavior and earthquake response to the fault. For regional seismotectonic studies, it is nearly impossible to completely evaluate the seismic history and recurrence interval of each fault by paleoseismic techniques. Therefore, this study uses statistical analysis of digital databases of all the earthquakes recorded since 1900 and known faults to distinguish earthquake faults and dormant faults over the last 110 years. We also use an analysis of centennial seismic performance of the faults and their migration over time, in order to build a current seismotectonic framework for the Songpan-Garze region. 


\section{Geological setting}

The study area is located in the northeast corner of the Tibetan plateau $\left(96^{\circ} \mathrm{E}-107^{\circ} \mathrm{E}, 30^{\circ} \mathrm{N}-35^{\circ} \mathrm{N}\right)$, which is one of the most seismically active regions in Central Asia (Figure 1 inset A) due to northward migration and collision of the Indian plate into the Eurasian plate. The continental crust in the Songpan-Garze area is predominately composed of folded Late Paleozoic lowgrade metamorphic basement rocks that are overlain by Triassic carbonates (Figure 1 inset B). The dominant structure grain of the region is characterized by NW-trending folds and thrust faults, which developed during continent-continent collision in the Mid to Late Mesozoic following closure of the paleo-Tethys Ocean (Xu et al., 1992). During the Jurassic and Cretaceous, the region was uplifted without any sediments formed, however, sporadic small plutons were emplaced. In response to increasing Indian-Eurasian plate collision during the Cenozoic, the dominant fold-thrust system was reactivated, and the Tibetan plateau was uplifted. Existing faults were reactivated as left-oblique reverse or left-lateral strike-slip faults (Zhang et al., 2003). The neotectonic activities in the region are correlated with local basin deposition.

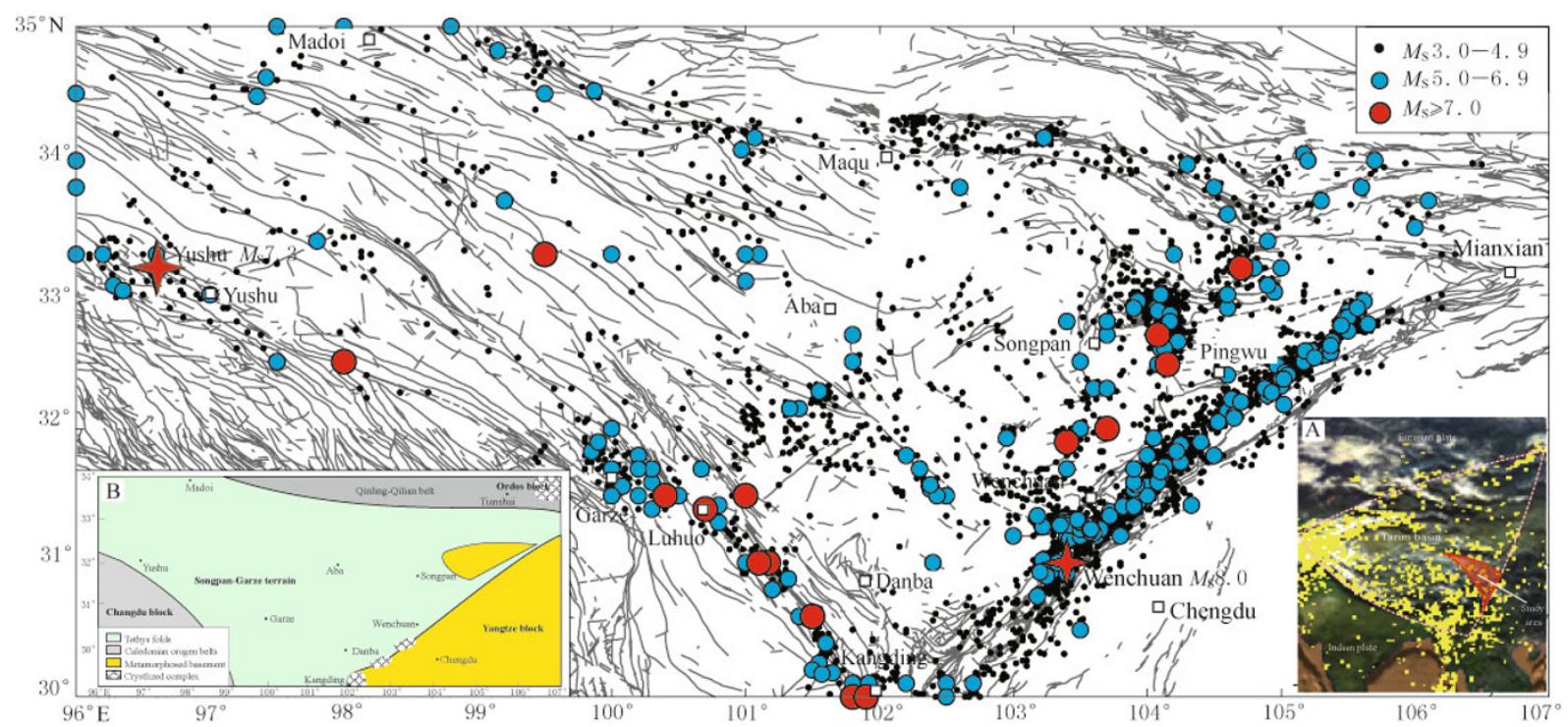

Figure 1 Location map of the Songpan-Garze region showing the distribution of mapped geologic faults and earthquakes in the study area. Inset A shows the study area with respect to Central Asia earthquake region. Inset B shows the geology and tectonic settings of the Songpan-Garze region.

\section{Songpan-Garze earthquake fault framework over the past 100 years}

Although earthquake nucleation is closely related to the present fault structure in theory, absolute correspondence between individual earthquakes and faults is not possible due to the combination of unknown downdip complexities along the fault planes (Chui, 2009) and hypocentral location positioning error. However, seismicity along a particular fault can be obtained using statistical analysis methods when an acceptable buffer size is given according to the occurrence and nature of the surface trace of the fault. The validity of the statis- tical analysis depends on the amount and precision of the data.

\subsection{Data and resources}

The fault database was established based on 1:200 000 scale digital geological mapping in China, which was edited by the Development Research Center of China Geological Survey. In total, 4781 faults ( $\geq 2 \mathrm{~km}$ length) were used in this study from the digital database (Figure 1). Detailed information is known about all faults, including fault length, surface trace location, dip direction, dip angle, and sense of displacement.

The earthquake database was compiled from the following digital repositories: http://data.earthquake.cn, 
http://www.csndmc.ac.cn, and http://data.earthquake. cn/data/. Of the compiled earthquake records, 77 records are of $M_{\mathrm{S}} \geq 4.7$ and lack accurate epicentral data because they come from disaster descriptions before 1900; 103 are instrument-recorded earthquakes of $M_{\mathrm{S}} \geq 4.7$ that occurred between 1900 and 1969, are of lower measurement accuracy, and mostly come from the International Seismological Center; and 5040 records are of $M_{\mathrm{S}} \geq 3.0$ that occurred during 1970-2011 and are the result of continuous observation of the seismic network in China, with most of the data quality being class 1 (horizontal location error $<10 \mathrm{~km}$ ) and class 2 (horizontal location error less than $25 \mathrm{~km}$ ). In total, 5220 earthquake records were used in this study, including 240 earthquakes of $M_{\mathrm{S}} 5.0-6.9$ and 17 strong earthquakes of $M_{\mathrm{S}} \geq 7.0$.

\subsection{Statistics and analysis method}

Seismicity for an individual fault is obtained by counting the number, magnitude, and time of earthquakes that are located within the buffer area of the particular fault being studied. The location and size of the buffer area is determined by the surface trace and down-dip projection of the fault, in consideration of the following general laws of fault development in the crust: (1) the influence area of fault activity, (2) the depth of brittle-ductile transition of fault behavior (Sibson, 1980), and (3) the dip direction and dip angle of the fault.

The affected faulting area was thought to be mainly related to the fault length (Sherman and Lobatskaya, 1972; Sherman, 2005). An empirical formula on the relation between the fault length and the radius of faulting influence area was proposed based on field investigation around Lake Baikal, Russia, as

$$
r \leq 0.5 \cdot K \cdot L^{c},
$$

where $r$ is the radius of the faulting influence area, $L$ is the fault length, $K$ and $c$ are the parameters of the regression equation, which are within $0.1-0.5$ and in 0.5-0.95, respectively. Because this empirical formula does not consider fault dip, it is only used for strike-slip faults.

Using a regional geothermal gradient of $32{ }^{\circ} \mathrm{C} / \mathrm{km}$ in Songpan-Garze and $22{ }^{\circ} \mathrm{C} / \mathrm{km}$ in Longmenshan regions (Xu et al., 2011) and a preferred distribution of foci in the study region, the depth of the brittle-ductile transition of fault behavior in a Quartz-feldspar stresssupporting crust is determined to be $20 \mathrm{~km}$.

The faults in the study region are divided into two types: dip-slip faults (normal fault and thrust) and strike-slip faults, based on the relationship between seismicity and fault occurrences (Wells and Coppersmith, 1994). Specifically, earthquakes occur on both sides of strike-slip faults, whereas earthquakes on dip-slip faults occur only within the hanging wall. Linear trains of earthquake foci that do not correlate to known fault traces are considered to be buried or unmapped faults, and are considered to have strike-slip displacement for statistical analysis. In the cases that the fault orientation is variable, an average dip direction is made in order to create a buffer that is parallel to the fault (Figures 2a, $2 \mathrm{~b})$. An example of the statistical analysis using a fault buffer area, as used in this study, is shown in Figure 2c.

In general, the down-dip projection of faults to depth is less than half that of the fault length. The calculation for buffer radius mentioned above is suitable for faults with surface length longer than $40 \mathrm{~km}$. In the case when the surface fault length is less than 40 $\mathrm{km}$, half the fault length is used for fault parameter $d$ (depth) for buffer radius calculations.

Because the statistical analysis was processed by computer, it is likely that some earthquakes were used more than once in the regions where faults are closely spaced. This is reasonable because of the complex relationship among faults as mentioned by Chui (2009).

\subsection{Centennial earthquake fault in the Song- pan-Garze region}

The statistical analyses based on the digital faults and the earthquake databases show that a total of 993 "centennial" earthquake faults, including 65 linear seismic chains, are identified from 4846 faults that are longer than $2 \mathrm{~km}$. Of the earthquake faults, nine have more than 100 earthquake records that occurred in the past 110 years. The remaining 3853 faults without seismic records are thought to be dormant faults, but this does not mean future earthquakes could not occur on these structures. Earthquake faults vary not only in frequency of earthquake occurrence, but also on earthquake strength as indicated by the weighted average of magnitudes (Table 1, Figure 3). In addition, the seismicity of individual earthquake faults reveals the recurrence interval and migration path of earthquakes foci along the faults.

The distinguished earthquake faults can be subdivided into several earthquake fault zones to be used to build up a seismotectonic framework for the SongpanGarze region. Subgroups include: the East Kunlun zone (Figure 3, numbers 1-5), the Bayan Har zone (Figure 3, numbers 8-17), the Gongma-Daqu zone (Figure 3, numbers 18-20), the Xianshuihe zone (Figure 3, numbers 21 and 22), and an oblique connection zone between 


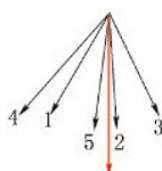

(a)

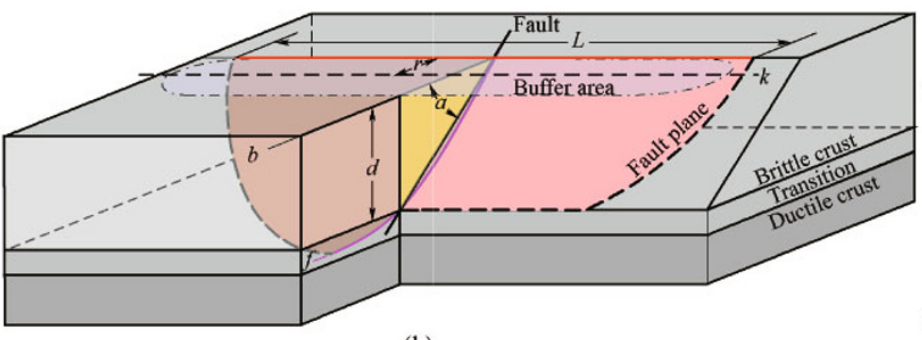

(b)

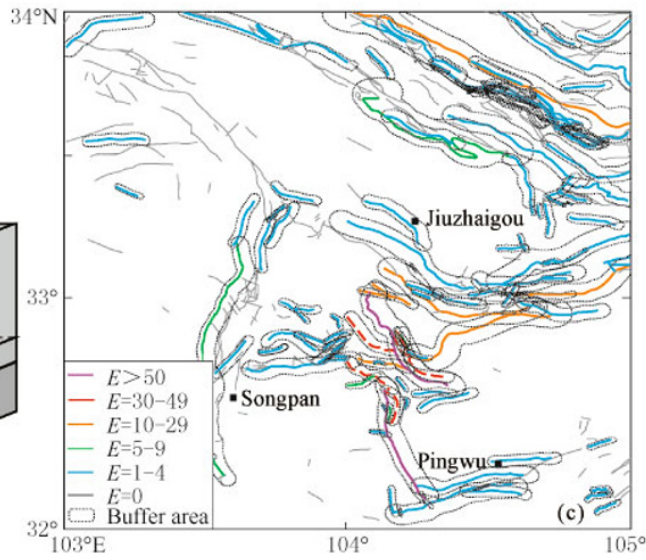

(c)

Figure 2 Buffer parameters of earthquake statistics on geological faults. (a) An average dip-direction for the fault with variable trends. The red long arrow in the left part is the average dip-direction, black arrows with number 1 to 5 are the true dip-directions for different part of the same fault and their locations are shown in the right part of the figure. (b) Sketch map showing the buffer calculation where $r$ is the radius of influence of fault activity, $a$ is dip angle of the fault angle, $d$ is depth of brittle-ductile transition, $L$ is fault length, $k$ is trending direction, $b$ is dip direction, and $f$ is actual occurrence of the fault. (c) An example showing statistical result using a fault buffer in the Songpan-Pingwu area (see Figure 1 for location), where $E$ is earthquake number of the fault.

Table 1 The earthquake fault variation on the number of earthquakes and the weighted average of magnitudes

\begin{tabular}{|c|c|c|c|c|c|}
\hline \multicolumn{3}{|c|}{ Statistic on earthquake number } & \multicolumn{3}{|c|}{ Statistic on the weighted average of magnitudes } \\
\hline $\begin{array}{l}\text { Number of } \\
\text { earthquakes }\end{array}$ & $\begin{array}{l}\text { Number of } \\
\text { faults }\end{array}$ & Percentage & $\begin{array}{c}\text { The weighted average } \\
\text { of magnitudes }\end{array}$ & $\begin{array}{l}\text { Number of } \\
\text { faults }\end{array}$ & Percentage \\
\hline 0 & 3853 & $79.5 \%$ & 0 & 3853 & $79.5 \%$ \\
\hline $1-9$ & 876 & $18 \%$ & $0.1-0.9$ & 735 & $15.2 \%$ \\
\hline $10-49$ & 90 & $1.9 \%$ & $1.0-4.9$ & 183 & $3.7 \%$ \\
\hline $50-99$ & 18 & $0.37 \%$ & $5.0-9.9$ & 40 & $0.8 \%$ \\
\hline$>100$ & 9 & $0.01 \%$ & $\geq 10$ & 35 & $0.7 \%$ \\
\hline
\end{tabular}

Note: The percentage indicates the percentage of the number of faults to the total number of faults (4 846).

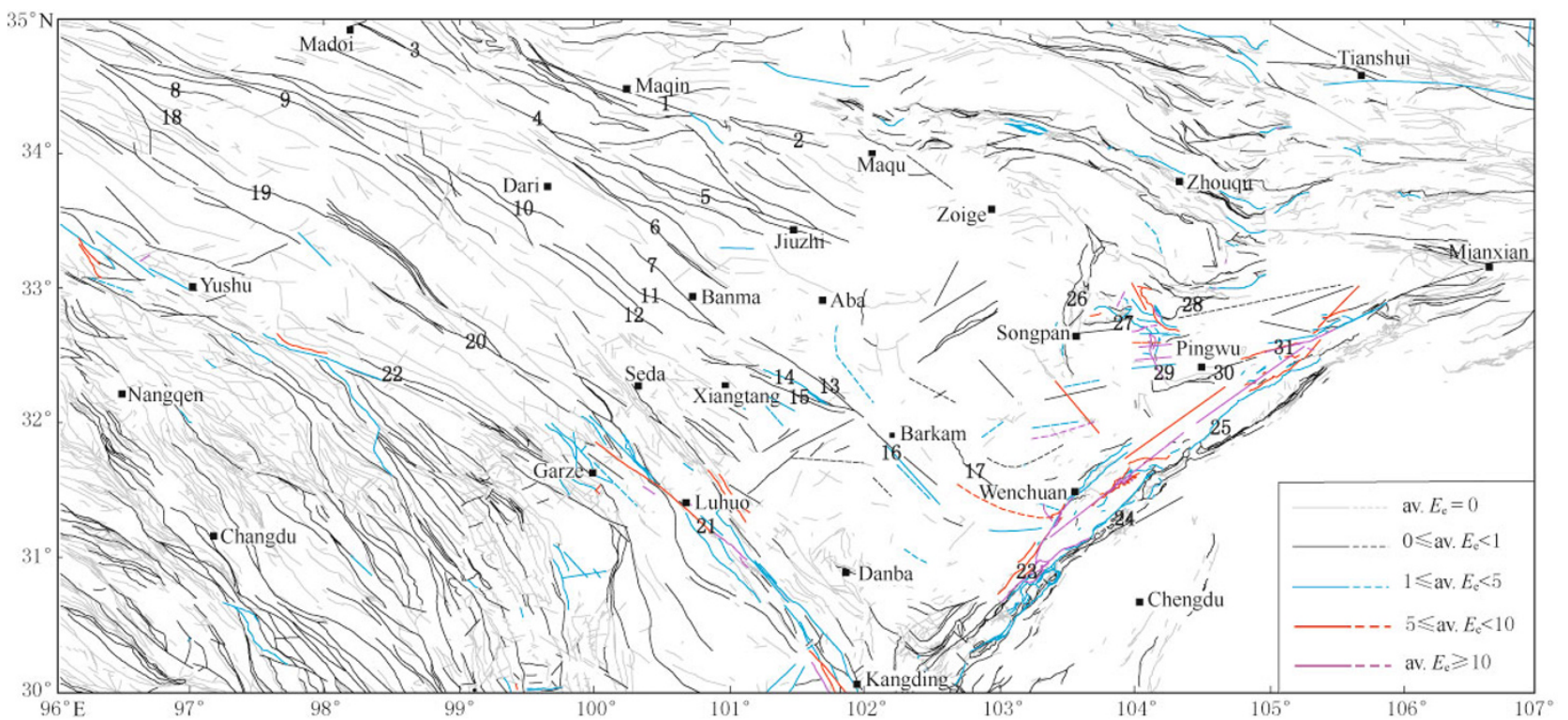

Figure 3 Various earthquake faults in the Songpan-Garze region. av. $E_{\mathrm{e}}$ is a parameter of weighted average of magnitudes on a fault. The numbers denote the subgroups. 
the East Kunlun and the Bayan Har zone (Figure 3, numbers 6,7 ). Of particular interest are the two sets of intertwined earthquake fault networks in the SongpanPingwu area (as described below). With the exception of the three earthquake fault zones that define the triangle study region, the central Gongma-Daqu zone and the Songpan-Pingwu network are the most significant. Earthquake faults shown in the southwest corner of Figure 3 are beyond the Xianshuihe earthquake zone and belong to another independent seismic structural system.

\section{Seismotectonics in the Songpan- Garze region}

The established earthquake fault framework, including the earthquake fault zones and the SongpanPingwu network mentioned above, developed during the last 110 years. A trend of gradual change of the seismotectonics in the region will be useful for understanding the earthquake behavior of the faults through time.

\subsection{Evolution of the earthquake faults in ten- year intervals}

The highest quality records within the earthquake database span the time interval from 1970 to 2011, which is conducive to developing a four decade-long picture of the progressive evolution of the earthquake faults (Figure 4). One of the periods of extreme seismicity occurred during the middle of the first decade, predominantly within the Songpan-Pingwu area. In that region, intermediate seismic activity was concentrated along the western segment of the East Kunlun zone and the middle segment of the Xianshuihe zone (Figure 4a, 1970-1979). Extreme seismicity in the Songpan-Pingwu area was followed by a 32 -year period of relative seismic quiescence before the Wenchuan $M_{\mathrm{S}} 8.0$ earthquake, which occurred on May 12, 2008 (Figure 4e). In the relatively quiet second (1980-1989 as shown in Figure 4b) and third (1990-1999 as shown in Figure 4c) decades, seismicity along both of the East Kunlun zone
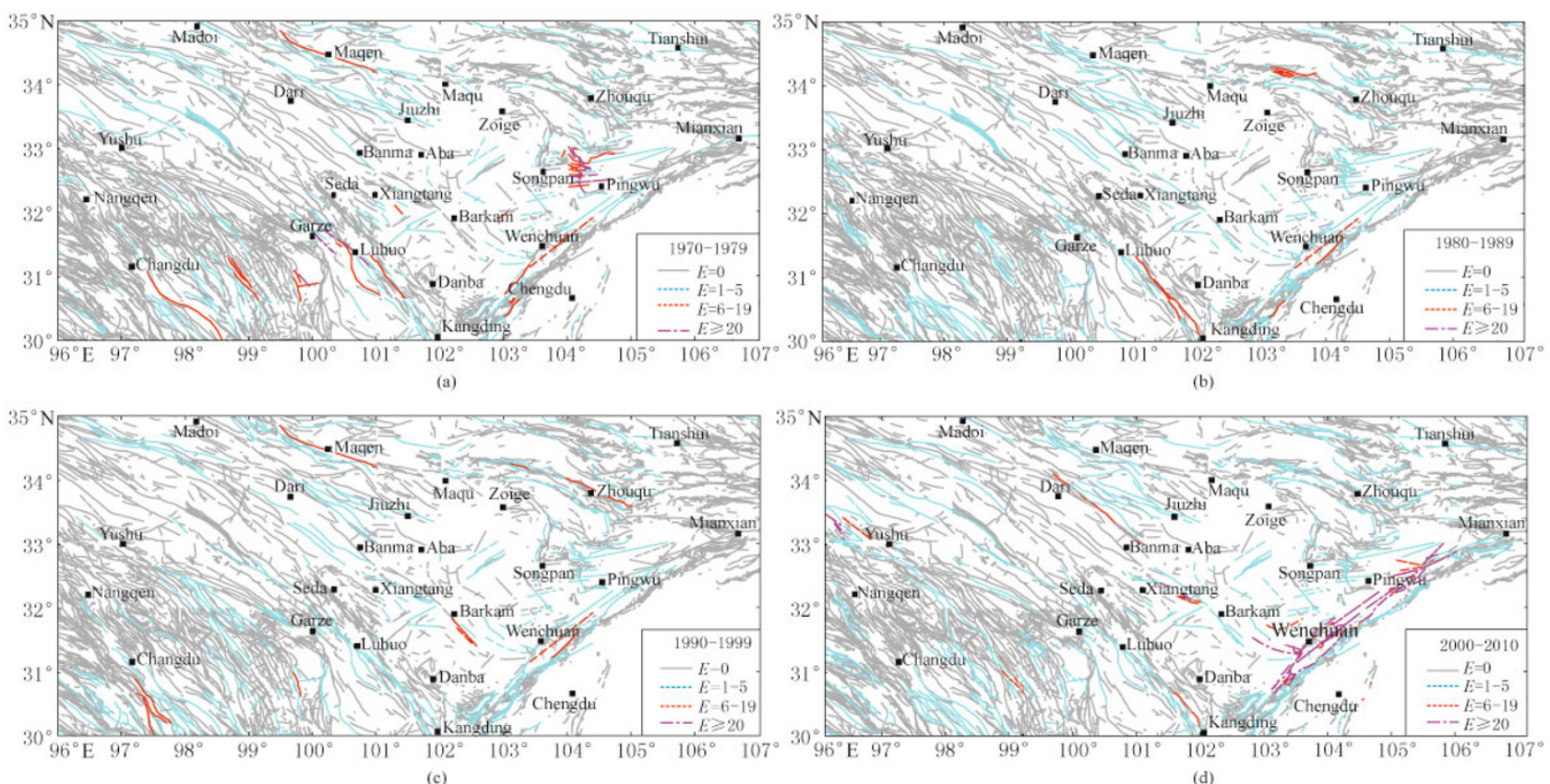

(d)

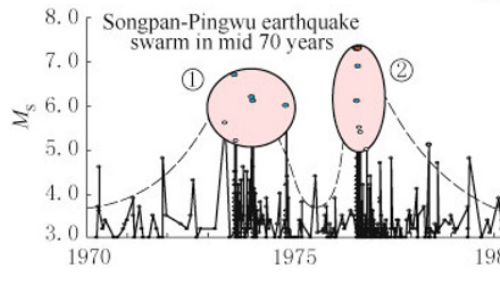

Wenchuan $M_{\mathrm{s}} 8.0$ earthquake On May 12, 2008

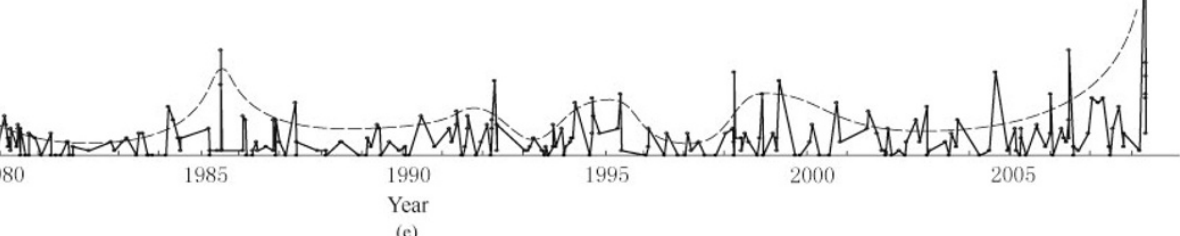

Figure 4 Changes of the earthquake faults in the Songpan-Garze region in 10-year intervals over the last four decade $(\mathrm{a}-\mathrm{d})$ and the 32-year period of relative seismic quiescence before the Wenchuan $M_{\mathrm{S}} 8.0$ earthquake (e) where (1) and (2) denote the reactived Baima arcuate faults and the Huya thrusts, respectively. 
and the Xianshuihe zone migrated eastwards. At the same time, increasing seismicity appeared in the central part of the triangular region along two SE-trending earthquake fault sets $3-5$ and 6-15 (Figure 3). These earthquake fault sets extended southeastwards during the early part of the fourth decade when the two sets became connected through oblique earthquake faults 6 and 7 , thereby strengthening seismic activity on the faults 13-15. In addition, a strong southeast seismicity migration along a segment of the Xianshuihe fault zone took place before the Wenchuan $M_{\mathrm{S}} 8.0$ earthquake occurred.

The Songpan-Pingwu seismic swarm occurred during the middle of the first decade and was characterized by strong, frequent seismicity over a short period (1973-1976), and was closely related to the
Chuanzhusi-Huanglong transpressional shear system of Mid-Pleistocene time (Zhang et al., 2010). In total, two earthquakes of $M_{\mathrm{S}} \geq 7.0$, seven earthquakes of $5.0 \leq M_{\mathrm{S}} \leq 6.9$, and several hundred earthquakes of $3.0 \leq M_{\mathrm{S}} \leq 4.9$ occurred in two clusters on the reactived Baima arcuate faults and the Huya thrusts (1) and (2) in Figures $4 \mathrm{e}$ and 5) as result of left-lateral strike-slip displacement. The Songpan-Pingwu earthquake network consists of 126 earthquake faults, which are distinguished from 462 faults with length greater than $2 \mathrm{~km}$.

Trends of the earthquake faults over the past 40 years show that seismic activity was converging toward the southeastern corner of the Songpan-Garze seismotectonic region when it migrated east or southeastward along each left-lateral strike-slip earthquake zones.

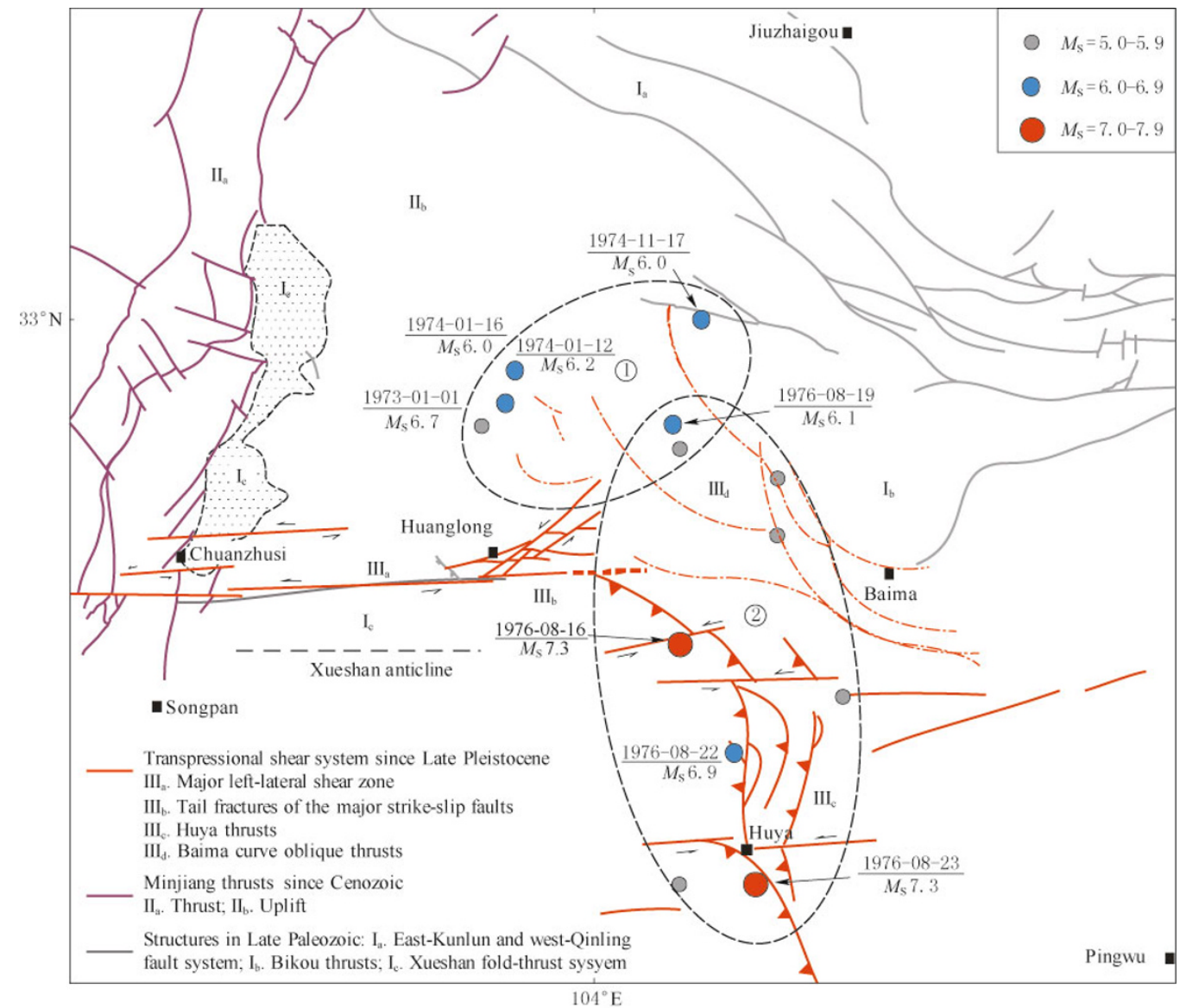

Figure 5 Relation between earthquakes and the transpressional shear system in the Songpan-Pingwu area. (1) and (2) denote the reactived Baima arcuate faults and the Huya thrusts, respectively.

\subsection{Present deformation velocities in the Songpan-Garze region}

Contour lines of the crustal deformation rate in Songpan-Garze region, based on 164 GPS observation sites over $\sim 10$ years before 2008 (Wang, 2008), are shown in Figure 6. It shows that the study region is restricted by three relatively stable velocity blocks including the Changdu to the southwest, the Sichuan basin to the east, and the Ordos to the northeast (domains 
I, II, III in Figure 6). Velocity blocks are delineated by major velocity gradients corresponding to the Xianshuihe, the East Kunlun and the Longmenshan earthquake zones. The velocity rate across Xianshuihe zone is $\sim 6.5$ to $8.6 \mathrm{~mm} / \mathrm{a}$ and is obviously strengthened at its mid-southeast segments, where the Gongma-Daqu zone converges (see Figure 3). By contrast, the velocity rate across the East Kunlun zone is less than $2.3 \mathrm{~mm} / \mathrm{a}$. Various velocities within the region (domain IV in Figure 6) can be divided into three velocity gradient fields $\left(\mathrm{IV}_{1-3}\right)$. The velocities in fields $\mathrm{IV}_{1}$ and $\mathrm{IV}_{2}$ decrease in opposite directions, reflecting a resistance to eastwards movement of the Sichuan basin block. The velocity field $\mathrm{IV}_{3}$ is the result of an obvious bend along the Xianshuihe fault zone, and the local presence of crystalline rocks (see description in the section of geology setting). Seven local velocity vortices (11-(7) in Figure 6) are related to seismic activation during the GPS observation.

The refined GPS velocity pattern in the study area provides information not only on the accordant transitional trends of the seismic activation and the increasing southeastward displacement rate, but also on the variable deformation that can be used to establish the seismotectonics in the Songpan-Garze region.

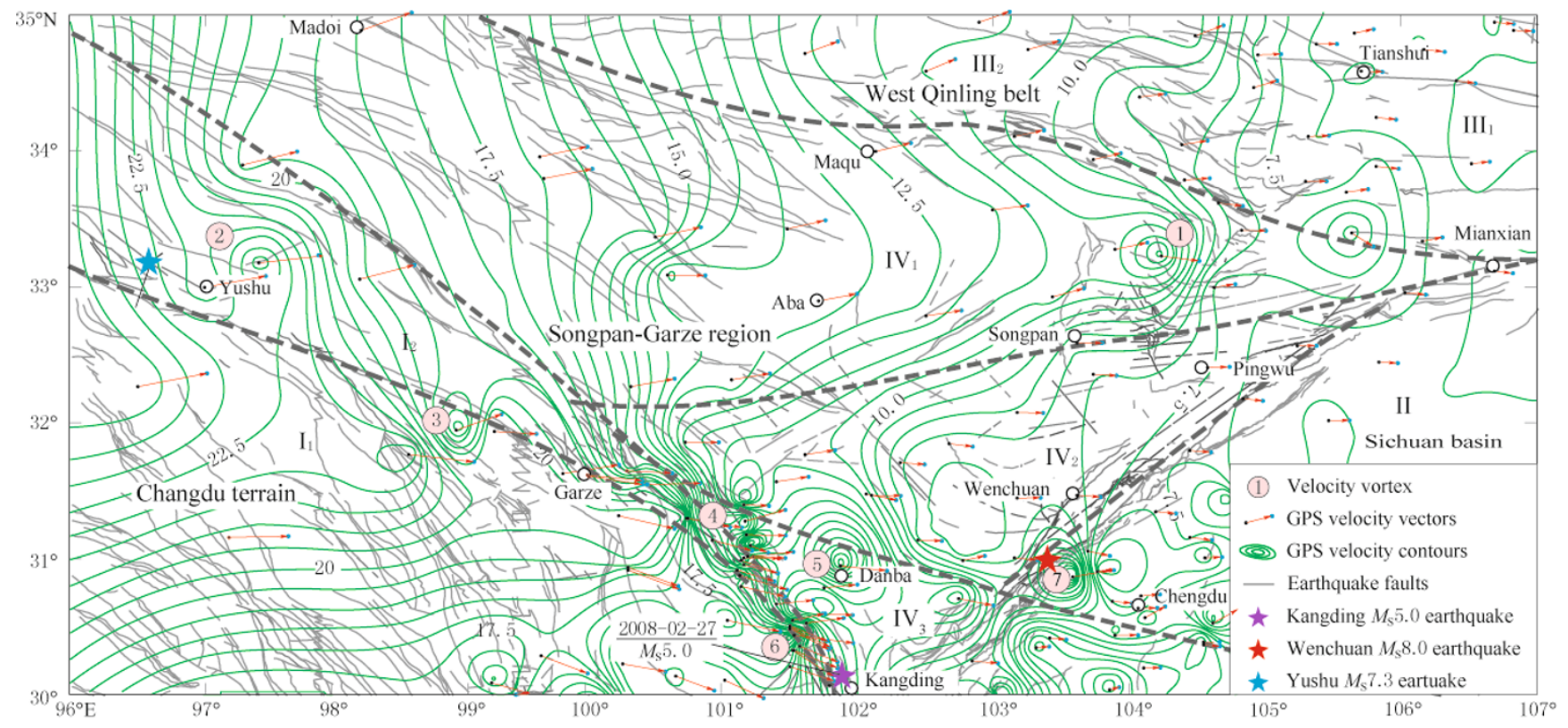

Figure 6 Present deformation domains in the Songpan-Garze region. $\mathrm{I}_{1}$. Changdu block, $\mathrm{I}_{2}$. Converging of the Xianshuihe faults and the Gongma-Daqu faults; II. Sichuan basin block; III $_{1}$. Ordos block, III $_{2}$. East Kunlun-West Qinling zone; $\mathrm{IV}_{1}$. Aba velocity field, $\mathrm{IV}_{2}$. Longmenshan velocity field, $\mathrm{IV}_{3}$. Kangding velocity field. Velocity vortices: (1) Baima-Huya, (2) Yushu, (3) Dege, (4) Luhuo, (5) Danba, (6) Kangding, (7) Dujiangyan.

\section{Discussion and conclusions}

This study uses statistical analysis based on geologic and tectonic setting, observed geologic faults, seismic records, and GPS data to develop the earthquake fault framework of the Songpan-Garze region over the past 110 years. Using variation in the timing of seismic activation, we show a centennial- and decadal-scale evolution of the region through to the present-day seismic dynamics, which provides a better understanding of the condition leading up to the May 12, 2008 Wenchuan $M_{\mathrm{S}} 8.0$ earthquake, in addition to earthquake potential in the near future (Zhang et al., 2012).
The Songpan-Garze seismic terrain is restricted by three relatively stable blocks, including the Changdu to the southwest, the Sichuan basin to the east, and the Ordos to the northeast. These blocks are bounded by three major earthquake fault zones, including the East Kunlun to the north, the Xianshuihe fault zone to the southwest, and the Longmenshan thrusts to the east. With the exception of the Songpan-Pingwu seismic swarm, which occurred in the mid-1970s, and the much higher displacement rate in the Xianshuihe zone, the increasing seismicity along Gongma-Daqu earthquake faults in the central part of the terrain is of significance.

Although current deformation of the study area 
is primarily driven by eastwards movement in response to eastward escape of the Tibetan plateau (Tapponier et al., 1982), internal motion within the triangular Songpan-Garze seismic terrain results from a gradual northeastward tectonic push. The northeastward push is a sub-component of the strain vectors, which are produced along the border of the terrain in response to southeastward bending of the fault trends, in addition to the westwards resistance of the Longmenshan thrust from the east. Left-lateral transpressional shearing is the dominant deformation mechanism within the terrain, and the inner deformation is likely to be the result of wedge effects.

Acknowledgements Thanks are given to the Development Research Center of China Geological Survey for providing the fracture and attribute data in 1:200 000 and 1:250 000 scales geologic map in the study area. Dr. Xiaojian Lu is given thanks for a careful proofreading of the earthquake catalogue that we used. This study was supported by the Major Project of Chinese National Program for Basic Research and Development (2008CB425703) and the International Cooperation Ministry of Science and Technology Key Project (2008DFA20700).

\section{References}

Chui G (2009). Shaking up earthquake theory. Nature 15: $870-872$.

Cyranoski D (2004). A seismic shift in thinking. Nature 431 : $1032-1034$.

Denham D (1988). Australian seismicity - the puzzle of the not-so-stable continent. Seis Res Lett 59(4): 235-240.

Sherman S I (2005). Tectonophysical analysis of the seismic process in zones of active lithospheric faults and medium-term earthquake prediction. Geofizicheskii Zhurnal 27(1): 20-38.
Sherman S I and Lobatskaya R M (1972). Correlation between lengths and depths of faults in the Baikal rift zone. Dokl AN SSSR 205(3): 578-581.

Sibson R H (1980). Transient discontinuities in ductile shear zone. J Struct Geol 2(1/2): 165-171.

Stein R S and Yeats R S (1989). Hidden earthquakes. Scientific Americans 260(6): 48-57.

Tapponier P, Peltzer G and Le Dain A Y (1982). Propagating extrusion tectonic in Asia: new insight from simple experiments with plastic. Geology 10(12): 611-616.

Wang M (2008). Latest progress on the aspect of GPS data processing and the effects on positioning. Recent Developments in World Seismology (7): 3-8 (in Chinese with English abstract).

Wells D L and Coppersmith K J (1994). New empirical relationships among magnitude, rupture area and surface displacement. Bull Seismol Soc Am 84(4): 974-1 002.

Xu M, Zhu C Q, Rao S and Hu S B (2011). Difference of thermal structure between eastern edge of Tibet Plateau and western Sichuan Basin. Chinese J Geology 46(1): 203-212 (in Chinese with English abstract).

Xu Z Q, Hou L W and Wang Z X (1992). Orogenetic Processes of the Songpan-Garze Orogenic Belt in China. Geological Publishing House, Beijing, 190pp (in Chinese with English abstract).

Zhang J S, Gan W J, Zhang M H, Huang X N and Liu F (2012). Seismotectonics since last 110 years and recent geodynamics in Songpan-Garze region. Earth Science Frontiers 19(5): 275-283 (in Chinese with English abstract).

Zhang J S, Huang X N, Niu X L and Liu F (2010). Chuanzhusi-Huanglong strike-slip faults and a transpressional shear system in Songpan-Pingwu area, northwestern Sichuan, China. Earth Science Frontiers 17(4): 1532 (in Chinese with English abstract).

Zhang J S, Li Y and Han Z J (2003). Deformation responses to eastwards escaping of the Qinghai-Tibet plateau and tectonics of the South-North Seismic Zone in China. Earth Science Frontiers 10(Suppl.): 168-175 (in Chinese with English abstract). 